\title{
Problems commonly encountered in quantitative thermographic electrical inspections
}

\author{
by SNELL R., Jr.
}

\author{
John Snell \& Associates 17 First Avenue Montpelier, Vermont 05602 (USA)
}

\begin{abstract}
The primary benefit of using infrared thermography to inspect electrical systems is qualitative in nature, i.e. locating problems. As reliable portable quantitative imaging systems have become available, thermographers have also begun relying almost entirely on radiometric temperature data as the primary means of prioritizing the severity of a problem. The validity of these methods is suspect due to the lack of standardization in data collection methods, the often poor understanding of radiometric measurements by maintenance thermographers, field conditions that vary widely enough to defy standardization, and the almost total lack of scientific research on the relationships among heat, time and failure in regard to the components being inspected.
\end{abstract}

\section{Introduction}

Infrared thermal imaging systems have been used in industrial and commercial maintenance thermography for three decades with great success. For electrical inspections the returns on the investment can be substantial [1]. The primary benefit of thermography for predictive and preventive maintenance (PPM) electrical inspections is qualitative, i.e. to locate problems. This can be done with great accuracy because components with problems nearly always have thermal patterns that differ from normally functioning components.

Once the anomaly has been identified, the maintenance staff can usually quickly determine the cause of the problem, often using additional, simple test methods, such as load reading or visual inspections. With that information in hand the priority of the repair is determined. To be most effective this process of prioritization is based on an often complex matrix of interrelated factors, including radiometric temperatures. Once the repair is made, hopefully prior to failure, the component can be reinspected to assure the integrity of the repair.

With the development of portable quantitative imaging systems thermographers began to experiment with using thermography to predict failure based on the belief that increasing temperature and the time to failure were directly related in a linear manner.

There is no doubt gross correlations do, in fact, exist between the increasing temperature of a problem component and it's eventual failure. The exact nature of the relationship, however, is not simple and is most often poorly understood. Additionally, quantitative measurements are frequently of dubious accuracy due to poor user training and data collection, widely variable field conditions, and the inherent limitations of radiometric measurement itself.

This paper serves to reaffirm the significant value of qualitative thermography for electrical inspections. However, because quantitative thermography predominates electrical inspection work at this time, I will also discuss some of its limitations as it is currently being used. Finally I will clarify a few issues that must be addressed if quantitative thermography is to mature as a predictive method for electrical inspections.

\section{Background}

Thermography was first used commercially for electrical inspections in the early 1960's. The industry grew slowly until the 1980's when the advent of accurate, portable quantitative instruments coincided with major investments in predictive maintenance. Since that time the use of thermography in maintenance has increased substantially.

Because thermography is used in diverse industries for countless applications, few focus points exist for the industry. The primary body of knowledge on the civilian side in the United 
States is the Proceedings from Themosense [2], an annual conference of thermographers held in the United States since 1977. Trade journal articles promote the acceptance of the technology but more often they create interest rather than provide substantial knowledge.

Thermography is still an unknown in most engineering curricula. Little publicly accessible, basic research has taken place. Only a few widely recognized standards exist. No viable standards exist in the United States for electrical inspections. The basic relationships between "hot spots" in an electrical component and its failure are very poorly understood. Until the Fall of 1993 no meaningful certification standards for thermographers existed.

An informal survey of three dozen reports collected at random from among the established thermographers in the United States showed the following problems related to current use of quantified thermography:

- "Reference temperature" was undefined in all but five reports.

- The term "ambient" was used in 2/3 of the reports but was defined in only five

- Two reports indicated that electric cabinet doors did not need to be opened

- One report employed a method known as "shooting the holes" for making qualitative observations through a small hole in the high voltage cabinet in the manner of a peep-hole camera. (This method has never been comprehensively and independently tested.)

- Two reports referenced quantitative "guidelines" developed by a training company. (The validity of these "guidelines" has never been independently substantiated.)

- Four reports made passing reference to other "standards" for electrical inspections, but in no case was a specific standard referenced.

- All but one report based prioritization of problems primarily on a radiometric measurement, either absolute or delta. In each of these cases a single set of temperature criteria was used for all types of components inspected.

- The temperature criteria cited varied widely and showed no discernible uniformity. No two sets of criteria were identical in all regards!

- More than half of the reports indicated that a priority based on temperature could be upgraded or downgraded based on a subjective assessment by the thermographer or customer as necessary.

- Electrical loads were reported in only half of the reports.

- No report, where inspections occurred out of doors, indicated the wind speed or other weather conditions.

- Approximately half the reports corrected for emissivity, even when delta measurements were made. None listed the source of their emissivity values.

- Nearly one third of the thermographers indicated they were "certified," all in one of several non-ASNT based programs. Many of these used a "certification" stamp on their reports suggestive of an engineer's seal.

- A subjective evaluation of the thermal images was made. Fully a third, including both color and black. and white images, were of such poor quality that the cause of the problems was not readily evident.

To any objective observer, this is a totally unacceptable situation. The same results from either a doctor or a car mechanic would produce a flurry of regulation and research. Is it not time to say "the king is wearing no clothing?" That we still find our industry in this situation thirty years after thermography was first commercially used is not only unacceptable, but also threatening to all of us.

\section{Problem areas in electrical inspections}

With today's high quality instruments it is quite possible to make accurate and repeatable radiometric measurements under controlled conditions using trained, experienced thermographers. But within the maintenance industry there are thousands of thermographers, with varying levels of qualification, operating in severe field conditions without standards. The results are far from optimum.

Why are results so varied and, generally, so poor? The difficulties encountered occur in the following general areas:

- The thermographer

- Inspection procedures 
http://dx.doi.org/10.21611/qirt.1994.007

- The radiometric instrument

- Ambient conditions

- The components being inspected

- The relationship between the findings and eventual failure

\subsection{The thermographer}

In the past 12 years we have worked with over six thousand thermographers in various training situations. It is clear this technology is not difficult to learn. We have found a little training can greatly accelerate the process. Our Level I and II training courses are each 30-40 hours. After the initial training the thermographer is fully prepared to gain hands-on experience. A year or two of field experience, with appropriate technical support, will usually result in real expertise.

Unfortunately many thermographers are not prepared in such a manner. Because of the lack of available study materials, many learn on there own. They frequently lack a solid, practical background in radiometric theory, with disastrous results. "On the job" training is too often little more than passing on the bad habits of the "teacher." Also, it is difficult to develop skills when conducting inspections a few times a year, a situation in which many thermographers find themselves.

Until the fall of 1993 no widely recognized standards existed to qualify and certify thermographers. In the previously mentioned survey of reports, one third indicated the thermographer was "certified." In 1993, at least three companies in the United States were "certifying" thermographers. In all cases "certification" was based on having passed simple, multiple-choice test, often "open book." In most cases, no actual experience, prior to attending one of the courses offered by these companies, was necessary to become "certified." Some of the tests were administered by mail so that it is probable some "certified" thermographers had no formal training what so ever.

In the fall of 1993 the American Society of Nondestructive Testing [3] (ASNT) published SNT-TC-1A-1992, Guidelines for Qualification and Certification

years ASNT has provided such standards in other test methods, especially in the nuclear power, petrochemical, and aerospace industries.

ASNT based standards require a thermographer to have (1) formal training, (2) experience, (3) passed a written general and practical exam, and (4) be periodically recertified. Certification is then made at one of three levels. Level I can set up the test equipment and gather data; Level II can interpret the data; and Level III can develop the test methods and standards.

As of this writing, at least one of the largest petrochemical companies in the United States is requiring all of their thermographs to be certified in accord with the ASNT standards. Inspectors from the two largest industrial insurance companies as well as many of the nuclear power plants are following suit. These standards, in conjunction with similar personnel qualification standards from the International Standards Organization (ISO) [4], will help to ensure thermographers who are "certified" in the future are also qualified.

\subsection{Inspection procedures}

Few inspection standards exist in the United States. For electrical inspections four standards or guidelines, each of limited acceptance, can be found:

- National Electrical Testing Association (NETA) [5]: The two standards are both minimal in scope regarding thermography. Inspections can be made with as little as $10 \%$ of design load (Maintenance) and $40 \%$ of design load (Acceptance). No provision is made for relating temperatures to changing loads. Findings are prioritized based on their radiometric temperature. However, no standard procedures for taking these readings are given.

- United States Nav [6]. Prioritization of problems is based on one of two sets of temperature based criteria which are used for all shipboard electrical and electronic equipment. The validity of the criteria has not been tested independently. Inspection procedures are fairly well documented, although the alarm limits are high enough to raise serious questions about personnel safety. 
- Infraspection Institute [7]: This training company publishes and sells their own set of "guidelines." These have not been reviewed or accepted by any nationally recognized standards organization. In these "guidelines" they attempt to assign a priority by comparing a corrected radiometric temperature to existing industry specifications for a component's maximum operating temperature. Despite a claim they are "traceable to ANSI Standards," neither the validity of the method or the correction procedures have been subjected to independent, scientific scrutiny.

- Nuclear Maintenance Applications Center (NMAC)[8]: The criteria used in this Guide prepared for the Electric Power Research Institute are more broadly based but still rely heavily on radiometric measurements. Procedures for inspection and a general criteria for assessing the priority are well thought out.

It is interesting to note that each of these standards allows the thermographer to change the quantitatively determined priority of a finding based on their subjective evaluation-and with little guidance as to how this should be done.

Two other groups are working on standards in the United States, including a committee of thermographers associated with ASNT. Their goal is to produce a "handbook" which would detail inspection procedures for numerous methods. This effort should come to fruition in 1996 [9].

ASTM has several committees working on standards related to infrared thermography. Standards already exist for inspecting roofs, bridge decks, buildings, and terminology. Committee E-7 on Nondestructive Testing [10], in particular, is leading the way but has been frustrated, like many volunteer organizations, by a lack of participation.

Until definitive standards for electrical inspections are formulated, tested, and accepted, quantitative thermography will be of limited value because of uncertainty about the validity and consistency of the data. One must question, however, whether or not it will even be possible to develop workable standards that enable thermographers to gather reliable data under the diverse and hostile circumstances they regularly encounter in the field.

It should be noted that the Danish Technological Institute [11] has recently published their excellent Guidelines. These attempt to correct some of the deficiencies outlined herein, and are based on actual research. Unfortunately, there appears to be a substantial downside to their standardization, in that the inspection is made more complex. They too allow the thermographer to reassess the priority of a problem based on their subjective evaluation, again with little guidance. This work continues to mature, however, and warrants close attention.

\subsection{The radiometric instrument}

The radiometric instruments available today are truly remarkable tools! Their sensitivity, accuracy, and sophistication are far in excess of the real needs of PPM thermographers. The instruments are tools that must be used properly.

Regardless, instruments must be calibrated and used properly. Too often I have observed thermographers relying on an instrument's readout even when it contradicts all reason. The worst case is perhaps the very popular point radiometers with laser assisted aiming. Novice users, often enticed by slick advertising, believe they can measure a spot the size of the laser's beam!

Other barriers exist to gathering accurate data in the field on a repeatable basis with any instrument, including:

- spatial resolution is often inadequate, especially for outdoor utility work. While adequate lenses are available, work is often done without them.

- short band systems, which are popular among utility companies, are especially sensitive to solar "glint" even while using solar filters. Low temperature problems can easily be missed, especially with light loads.

- emissivity values for common component materials are poorly defined and often not wave band specific.

\subsection{Ambient conditions}

Ambient conditions can vary dramatically and with significant, poorly understood, implications. Foremost for outside work is convective cooling by the wind, although convective 
http://dx.doi.org/10.21611/qirt.1994.007

air flows inside can also be significant. The influence of the wind has been generally discussed [12], but it's actual influence in specific instances is far more complex and in no case has this been adequately studied.

Nothing has been published regarding the quantifiable influences of the sun and solar loading on electrical inspections. While it is generally believed the sun has a linear, additive influence, as do changes in ambient air temperatures, this has not been systematically tested. Informal observations, as well as an even cursory examination of the scientific principals involved, suggest the behavior is much more complex.

Changes in ambient can also unexpectedly affect the way problems are typically reported and prioritized. If the reference temperature is measured as the back of a cabinet, as it often is, what happens when the cabinet contains a "hot spot?" The reference changes as the temperature of the problem changes? Further, do data collection procedures account for how long the door has been open before the "reference" is measured?

Surface moisture is also an influence outdoors. Evaporative cooling can be a significant influence, the impact of which, again, is not fully understood by most PPM thermographers.

The only thing that appears to be true about ambient influences is that fewer components fail during windy and colder times, or in air conditioned areasl Sadly, this fact is lost on many PPM thermographers who fail to consider their findings in relationship to "worst casen conditions that may occur in the future.

\subsection{The components being inspected}

The electrical equipment itself presents countless problems for thermographers who want meaningful quantified data. The difficulties fall into two general areas, (1) heat transfer from the site of high resistance within the component to its surface; and (2) radiation from the component's surface to the radiometer. Informal observations suggest radiometric field measurements of electrical components have a poor correlation with the actual thermal conditions at the contact surface. This is due to the fact that the point of high resistance, and consequent heat generation, is often connected in a thermally indirect fashion to the observed surface. Evidence is clear in cases where metal at the contact surface has reached the melting point but radiometric readings are below that.

Heat transfer varies with the component's shape and orientation as well as its mass. Can meaningful standards be developed for the many variations seen in components being inspected? Again, the Danes have done an excellent job generally of quantifying these relationships. Unfortunately the task of applying their guidelines in the field is too subjective to be easily standardized.

Clearly the type of material from which a component is made is significant. And yet none of the commonly used "standards" account for this. The melting point of aluminum $\left(1220^{\circ} \mathrm{F} / 660^{\circ} \mathrm{C}\right.$ ) is far below that of common bronze alloys (approximately $1600^{\circ} \mathrm{F} / 1140^{\circ} \mathrm{C}$ ). Additionally materials may be damaged when subjected to much lower temperatures over time. Copper, for instance, can be annealed, or lose its spring tension, after a mere thirty days at $212^{\circ} \mathrm{F} / 100^{\circ} \mathrm{C}$.

Often a direct view of the component, to say nothing of the contact surface, is impossible. Even with cabinet doors open, breaker stabs to the bus, or contact surfaces within a switch, cannot be viewed directly. Again, what is clear to anyone who has conducted electrical inspections is that temperatures within a component, at the contact surface, can reach the metal's melting point while surface temperatures are far below that. We are able only to measure surface temperatures, and then, only with limited accuracy.

These difficulties are compounded by the fact that the electrical components are most often made of materials having low emissivities. It is not always possible to measure emissivity accurately because equipment remains energized. While corrections in the field are theoretically possible, the practical result of correcting for both emissivity and background temperatures under these diverse, uncontrolled conditions is that radiometric measurements are often highly variable and unreliable. The real problem, however, is that low temperature problems will not be seen at all when the component has a thermally reflective surface.

Obviously heat output_and thus temperature-is related to electrical loading. Both can vary significantly for any single component over time. However, radiometric measurements 
without load information are meaningless. The literature frequently sites Ohm's Law as a means of characterizing the relationship between temperature and load. Such is not the case! Through simple experiments, both Baird [13] and the Danes [14] have come closer to describing the truth of this relationship, but it is clearly not a simple one, especially in the field.

Ohm's Law can, of course, be used to relate heat output with load. Thus when current doubles, heat output quadruples; when current triples, heat output goes up nine times. The relationship between heat output and temperature, however, is much more complex, and is not fully measurable in the field. What is clear, however, is that heat transfer to ambient surroundings by all modes increases with a temperature difference. Thus component temperatures begin to slow their rate of increase as the connection heats up. It is doubtful, however, that the precise rate of reduction is predictable over the range of changes that are normally encountered in the field.

\subsection{The relationship between the findings and eventual failure}

The meaning or value of data that is gathered is not well understood. Beliefs or "rules of thumb" have evolved into "standards" without being questioned thoroughly or tested systematically. Fundamental to all these beliefs is the notion that the higher the measured temperature, the more severe the problem and, conversely, the lower the measured temperature, the less severe the problem. Unless changes in loads and ambient conditions are taken into account, nothing could be further from the truth!

Alarm limits have not been determined for most components. Many materials and some components do, in fact, have "not to exceed" temperature limits established by the manufacturer. However, these prove to be very conservative and cannot be readily translated to the needs of thermographers looking at changes on a specific contact surface.

While many thermographers mistrust the accuracy of "absolute" or radiometric measurements, they tend to rely on "delta" measurements. These are measurements of temperature differences either from phase to phase; from one piece of equipment to another similar one; or for the same equipment over time. While "delta" measurements can be very useful in trending changes and suggesting a progression toward failure, great care must be taken to eliminate all variables but the change in temperature. And even at that point, we know little about how components approach thermal failure. It is clearly ridiculous to think that one set of temperature based criteria can be used to prioritize all problems regardless of component type.

The relationship between increased component temperature and failure is very poorly understood. We must, perhaps, tum to metallurgy to see that the problems are complex. Failure can occur due to melting or annealing. But resistance and rates of oxidation can also change with temperature, further complicating an already complex set of relationships. A worst case example of misdiagnosing a problem based on its temperature involves components that have gotten hot enough to weld themselves together. They often appear cool-and consequently not serious-until the reheating cycle begins again. At no time, however, regardless of their temperature, could they be acceptable.

\section{Further work is needed}

Some thermographers have begun to question the foundations of quantitative thermography for electrical inspections. This is healthy. For quantitative electrical inspections to gain their fullest value as a predictive tool, the following issues, among others, must be better understood:

- the relationship between load and temperature

- the impact of ambient changes on measured temperatures, both delta and absolute

- the relationship among heat, time, and failure for various components

Several specific actions could dramatically improve the reliability of quantified electrical inspections:

- creation of "standard reference thermograms," or standard thermal pattems for normally operating components, provided by the component manufacturer

- specification and adoption of ASNT or ANSI/ISO based personnel qualification and certification standards 
http://dx.doi.org/10.21611/qirt.1994.007

- adoption of standard data collection procedures and terminology

- creation of an accessible international electronic data base of thermal findings using standardized data collection and entry procedures

- develop inclusive procedures to determine the repair priority of a finding

\section{Conclusions}

For the near future, the value of thermography in electrical inspections will continue to be primarily qualitative. That value should not to be underestimated. With it we can accomplish the remarkable task of identifying, from thousands of potential problems, the few that are, in fact, problems.

Quantitative thermography has yet to find its true and proper value. Because quantitative thermography may be impossible to fully standardize, subjectivity will still play an important role in determining the severity of the problems located. Thermographers must become better qualified and rigorous personnel standards based on ASNT and ANSI/ISO can accomplish that. If thermographers can also begin to rely on an improved knowledge base and use more workable standard inspection practices and data collection procedures, we will be one step closer using this remarkable technology fully.

Examining the current use of quantitative thermography for electrical inspections, and questioning the limits it has, is vital to understanding how to better use both modes of thermography.

\section{REFERENCES}

[1] GREENE (V.J.), - Infrared Inspection, The Locomotive, Vol. 64, No. 5, Spring, 1985

[2] Proceedings of Thermosense, available from SPIE, PO Box 10, Bellingham, WA 98227

[3] SNT-TC-1A-1992, Guidelines for Qualification and Certification of Personnel, American

Society for Nondestructive Testing (ASNT), PO Box 28518, Columbus, Ohio 43228-0518, USA, (614) 274-6003/fax (614) 274-6899.

[4] International Standards Organization (ISO), available from American National Standards Institute (ANSI), 11 West 42nd St., New York City, New York 10036 (USA).

[5] NETA Maintenance Testing Specifications and NETA Acceptance Testing Specifications, National Electrical Testing Association (NETA), PO Box 687, Morrison, CO 80465

[6] Infrared Thermal Imaging Survey Procedure for Electrical Equipment, MIL-STB-2194, Naval Publications and Printing Service, 700 Robbins Ave., Bldg. 4D, Philadelphia, PA 19111

[7] Guideline for Infrared Inspection of Electrical and Mechanical Systems, Infraspection Institute, 1791-C Shelbume Rd. Sherbume, Vermont 05842, USA

[8] Infrared Thermography Guide; NP-6973, Electric Power Research Institute, 3412 Hillview Avenue, Palo Alto, Califomia 94304 USA

[9] Communications with Chairman Russ Mack, DOW USA, NDT Development B-2406, 2301 N. Brazosport Blvd., Freeport, Texas 77541-3257

[10] Communications with Chairman Leonard Mordfin, Committee E07.10.04 on Infrared Methods, ASTM, 1916 Race St., Philadelphia, PA 19103-1187

[11], [12], [14]Guidelines for Thermographic Inspection of Electrical Installations, Danish Technology Institute, Department of Energy Technology, Gregersensvej, PO Box 1412, DK2630 Taastrup, Denmark

[13] BAIRD, (G.), Quality aspects of electric utility inspections, SPIE Volume 581, Thermosense VIII (1986) 